\title{
Fatigue crack growth in a nickel-based superalloy at elevated temperature - experimental studies, viscoplasticity modelling and XFEM predictions
}

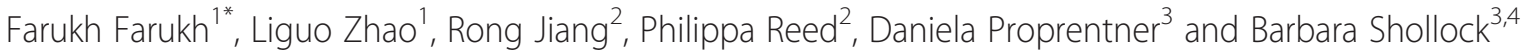

\begin{abstract}
Background: Nickel-based superalloys are typically used as blades and discs in the hot section of gas turbine engines, which are subjected to cyclic loading at high temperature during service. Understanding fatigue crack deformation and growth in these alloys at high temperature is crucial for ensuring structural integrity of gas turbines.
\end{abstract}

Methods: Experimental studies of crack growth were carried out for a three-point bending specimen subjected to fatigue at $725^{\circ} \mathrm{C}$. In order to remove the influence of oxidation which can be considerable at elevated temperature, crack growth was particularly tested in a vacuum environment with a focus on dwell effects. For simulation, the material behaviour was described by a cyclic viscoplastic model with nonlinear kinematic and isotropic hardening rules, calibrated against test data. In combination with the extended finite element method (XFEM), the viscoplasticity model was further applied to predict crack growth under dwell fatigue. The crack was assumed to grow when the accumulated plastic strain ahead of the crack tip reached a critical value which was back calculated from crack growth test data in vacuum.

Results: Computational analyses of a stationary crack showed the progressive accumulation of strain near the crack tip under fatigue, which justified the strain accumulation criterion used in XFEM prediction of fatigue crack growth. During simulation, the crack length was recorded against the number of loading cycles, and the results were in good agreement with the experimental data. It was also shown, both experimentally and numerically, that an increase of dwell period leads to an increase of crack growth rate due to the increased creep deformation near the crack tip, but this effect is marginal when compared to the dwell effects under fatigue-oxidation conditions.

Conclusion: The strain accumulation criterion was successful in predicting both the path and the rate of crack growth under dwell fatigue. This work proved the capability of XFEM, in conjunction with advanced cyclic viscoplasticity model, for predicting crack growth in nickel alloys at elevated temperature, which has significant implication to gas turbine industries in terms of "damage tolerance" assessment of critical turbine discs and blades.

Keywords: Fatigue crack growth; Crack growth rate; Viscoplasticity; Finite element analysis; Nickel base superalloy

\footnotetext{
*Correspondence: F.farukh@Lboro.ac.uk

'Wolfson School of Mechanical and Manufacturing Engineering,

Loughborough University, Loughborough LE11 3TU, UK

Full list of author information is available at the end of the article
} 


\section{Background}

Nickel-based superalloys are designed to provide superior combination of properties such as strength, toughness and thermal performance which make them suitable for structural components undergoing high mechanical and thermal stresses. The typical application of these alloys are in turbine blades and discs in the hot section of gas turbine engines, which are subjected to cyclic loading at high temperature during their service life. Understanding the fatigue damage behaviour, associated with crack initiation and propagation, of nickel-based superalloys at high temperature is crucial for structural integrity assessment of gas turbines based on the "damage-tolerance" approach.

The mechanical behaviour of this type of material involves time consuming and costly tests under cyclic load with superimposed hold time at maximum or minimum load level, representative of typical service loading conditions. The material in such circumstances undergoes a combination of creep-fatigue deformation. In particular, numerous studies have been performed to investigate the creep-fatigue crack growth in nickel superalloys, focusing on the effect of various fatigue loading parameters (e.g. waveform, frequency, ratio and dwell periods) on crack propagation (Pang \& Reed 2003; Dalby \& Tong 2005). Crack growth rates (da/dN) have been correlated with stress intensity factor range $(\Delta \mathrm{K})$ to quantify the damage tolerance capability of the material. This approach has been used for crack growth characterisation in various engineering materials for over four decades (Suresh 1998). However, the methodology is largely empirical and does not consider the physical mechanism of crack tip deformation, especially the cyclic plasticity, which is believed to control crack growth behaviour in metallic alloys.

Crack growth simulation using finite element has been extensively carried out to study crack-tip plasticity and associated crack growth behaviour including closure effects (Sehitoglu \& Sun 1989; Pommier \& Bompard 2000; Zhao et al. 2004). In terms of constitutive models, most work is limited to time-independent plasticity, with a lack of capability to predict crack growth path and rate. Recently, Zhao and Tong (Zhao \& Tong 2008) used a viscoplastic constitutive model to study the fundamental crack deformation behaviour for a nickel based superalloy at elevated temperature, focusing on the stressstrain field near the crack tip. Results showed distinctive strain ratchetting behaviour near the crack tip, leading to progressive accumulation of tensile strain normal to the crack growth plane. Low frequencies and superimposed hold periods at peak loads significantly enhanced strain accumulation at crack tip, which is also the case for a growing crack. A damage parameter based on strain accumulation was used to predict the crack-growth rate for different fatigue loading conditions. The crack was assumed to grow when the accumulated strain ahead of the crack tip reaches a critical value over a characteristic distance. The average crack growth rate was then calculated by dividing the characteristic distance with the recorded number of cycles. Although predictions are in good agreement with experimental data, the work was unable to predict the process of crack growth as it was based on stationary crack analyses only.

The extended finite element method (XFEM) has received considerable attention since its inception in 1999 by researchers dealing with computational fracture mechanics (Moës et al. 1999). The method has been widely applied to a variety of crack problems involving frictional contact (Dolbow et al. 2001), crack branching (Daux et al. 2001), thin-walled structures (Dolbow et al. 2000) and dynamic loading (Belytschko et al. 2003). The approach was also capable of modelling problems such as holes and inclusions (Sukumar et al. 2001), complex microstructure geometries (Moës et al. 2003), phase changes (Chessa et al. 2002) and shear band propagation (Samaniego \& Belytschko 2005). For instance, Stolarska et al. (Stolarska et al. 2001) used the extended finite element method, in conjunction with the level set method, to solve the elastic-static fatigue crack problem. The XFEM is used to compute the stress and displacement fields necessary for determining the rate of crack growth. Mariani and Perego (Mariani \& Perego 2003) utilized the cubic displacement discontinuity, which is able to reproduce the typical cusp-like shape of the process zone at the tip of a cohesive crack, to study the mode I crack growth in a wedge-splitting test and the mixed mode crack growth in an asymmetric three-point bending test. Cubic displacement discontinuity was also used in (Bellec \& Dolbow 2003) as enrichment functions for modeling crack nucleation, which again allowed the reproduction of the typical cusp-like shape of the crack-tip process zone. Budyn et al. (Budyn et al. 2004) used the vector level set method, developed by Ventura et al. (Ventura et al. 2003), for modeling the evolution of multiple cracks in the framework of the extended finite element method. Nagashima et al. (Nagashima et al. 2003) applied the XFEM to two-dimensional elastostatic bimaterial interface cracks problem. They used an asymptotic solution to enrich the crack tip nodes, and adopted a fourth order Gauss integration for a 4-node isoparametric element with enriched nodes. Despite increasing attempts to model crack growth using XFEM, to the authors' knowledge, no work has been carried out by adopting the criterion of strain accumulation, which is the distinctive deformation feature at a crack tip under fatigue loading conditions (Zhao \& Tong 2008). The majority of the work used the maximum principal stress or strain criteria which are not suitable to model crack growth under fatigue 
loading conditions as such simple criteria do not consider damage accumulation during the fatigue process.

In this paper, crack growth in a nickel-based superalloy LSHR (Low Solvus High Refractory) has been studied, both experimentally and computationally, under high temperature fatigue loading conditions. Fatigue tests were carried out for a three-point bend specimen in vacuum under a trapezoidal loading waveform with different dwell times. A cyclic viscoplastic constitutive model is used to model crack-tip deformation and to predict crack growth. The constitutive model, with parameters fitted from test data, was programmed into a user-defined material subroutine (UMAT) interfaced with ABAQUS for crack tip deformation analyses. With the assistance of the extended finite element method, the viscoplasticity model was also applied to predict crack growth based on plastic strain accumulation at the crack tip that was calculated by the UMAT. Predicted crack growth was compared with that obtained experimentally for selected loading range and superimposed dwell times.

\section{Methods}

\section{Experimental studies}

The material used in this study was powder metallurgy LSHR superalloy provided by NASA. The material possesses excellent high temperature tensile strength and creep performance as well as good characteristics due to low $\gamma^{\prime}$ solvus temperature (Gabb et al. 2005). Its chemical composition is $12.5 \mathrm{Cr}-20.7 \mathrm{Co}-2.7 \mathrm{Mo}-3.5 \mathrm{Ti}-3.5 \mathrm{Al}-0.03 \mathrm{C}$ $0.03 \mathrm{~B}-4.3 \mathrm{~W}-0.05 \mathrm{Zr}-1.6 \mathrm{Ta}-1.5 \mathrm{Nb}$ and balance $\mathrm{Ni}$ in weight percentage (Jiang et al. 2014). The alloy has a two-phase microstructure consisting of - matrix and strengthening -
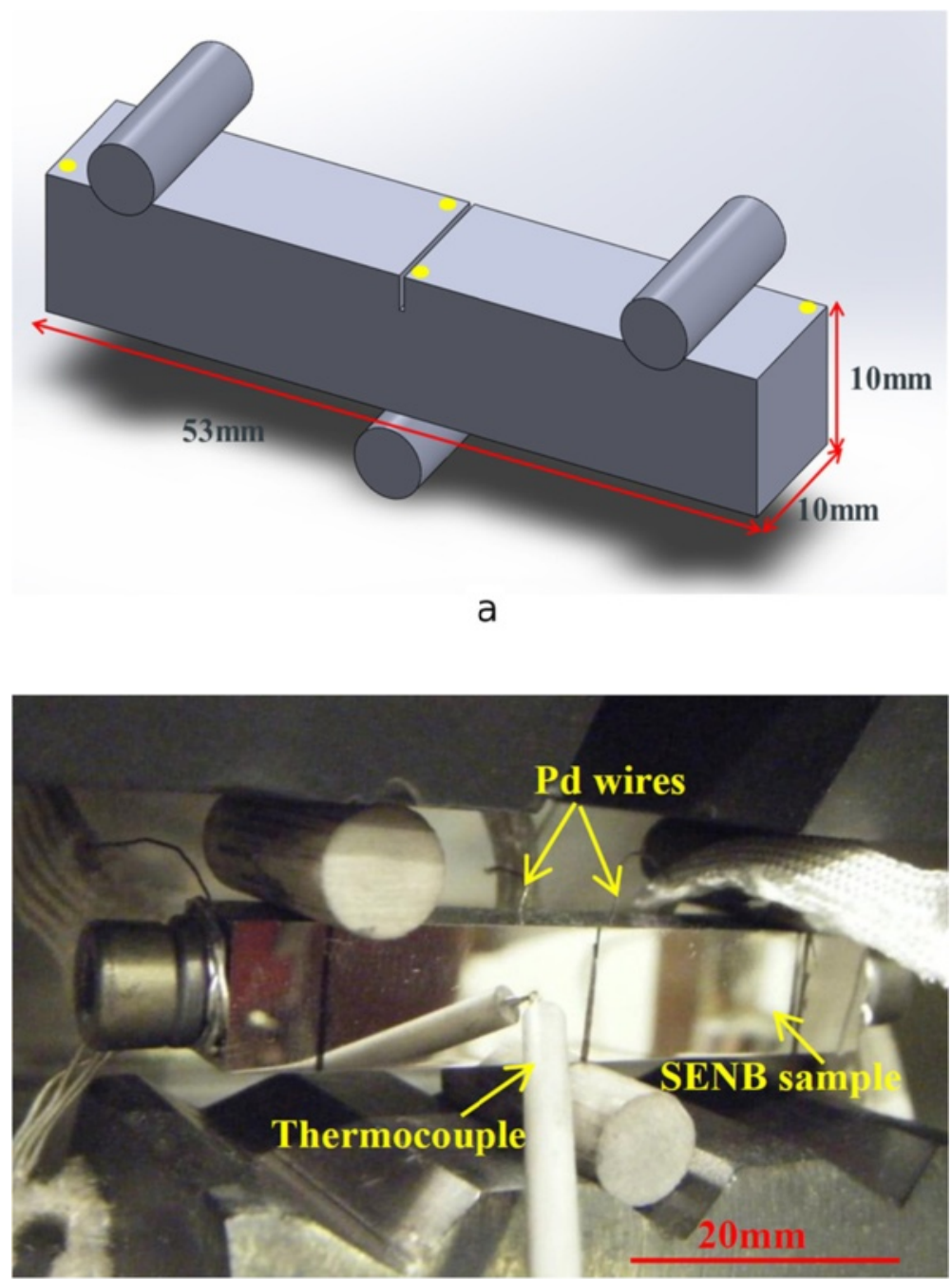

b

Figure 1 Illustrations of (a) SENB specimen geometry and (b) experimental set-up. Yellow circles on top surface indicate the positions of potential drop wires. 
precipitates $\mathrm{Ni}_{3}(\mathrm{Al}, \mathrm{Ti}, \mathrm{Ta})$ which are responsible for the elevated temperature strength of the alloy. The material was supersolvus heat treated to yield a coarse grain microstructure, which has a wide range of grain size, i.e. $10-140 \mu \mathrm{m}$. The average grain size was found to be $36.05 \pm 18.07 \mu \mathrm{m}$.

Fatigue crack growth tests were conducted on single edge notched bend (SENB) specimens with dimensions of $53 \mathrm{~mm} \times 10 \mathrm{~mm} \times 10 \mathrm{~mm}$ (Figure 1a). The notch with a depth of $2.5 \mathrm{~mm}$ was machined by electrostatic discharge machining in the middle of the specimen, which acted as a stress concentrator to initiate the crack during the test. Tests were conducted under three-point bend on an Instron servo-hydraulic testing machine in vacuum at $725^{\circ} \mathrm{C}$. The experimental set-up is shown in Figure $1 \mathrm{~b}$. The tests were load-controlled with a trapezoidal loading waveform (1-1-1-1, 1-20-1-1 and 1-90-1-1) and a load ratio of $\mathrm{R}=0.1$. Here, trapezoidal loading waveform " $1-\mathrm{X}-1$ 1 " means that the sample was loaded to the maximum load level in 1 second, held at the maximum load level for $\mathrm{X}$ seconds $(\mathrm{X}=1,20$ and 90 in this paper), unloaded to the minimum load level in 1 second and held at the minimum load level for 1 second. The maximum load was chosen to be $2.615 \mathrm{kN}$. Prior to crack growth test, the specimen was pre-cracked at ambient temperature using a load shedding method which has a sinusoidal waveform, a ratio of 0.1 , a frequency of $20 \mathrm{~Hz}$ and an initial stress intensity factor range $(\Delta \mathrm{K})$ of $20 \mathrm{MPa} \sqrt{\mathrm{m}}$. The $\Delta \mathrm{K}$ was reduced by $10 \%$ after the crack had grown out of the crack-tip plastic zone until reached $15 \mathrm{MPa} \sqrt{ } \mathrm{m}$. After pre-cracking, the vacuum chamber was evacuated to $1 \times 10^{-5} \mathrm{mbar}$, and then heated to $725^{\circ} \mathrm{C}$ using four high intensity quartz lamps. The temperature of the specimen was monitored and controlled to an indicated $\pm 1^{\circ} \mathrm{C}$ using a thermocouple which was spot welded to the specimen. For interrupted tests, crack growth testing was stopped when $\Delta \mathrm{K}=40 \mathrm{MPa} \sqrt{\mathrm{m}}$. Crack length was monitored and recorded by a direct current electrical potential drop method. A post-test calibration of the potential drop correlation to actual crack length was performed based on the initial and final crack lengths measured on the fracture surface (or both side surfaces and sectioned central plane for tests stopped at a certain $\Delta \mathrm{K}$ level). The fatigue crack growth rates were derived from the curve of the variation in the electrical potential with time by the secant method.

\section{Material model}

The material model used is essentially the constitutive equations developed by Chaboche (Chaboche 1989),

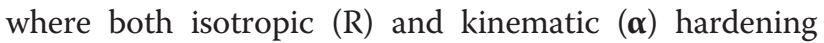
variables are considered during the transient and saturated stages of cyclic response. Within the small strain hypothesis, the strain rate tensor $\dot{\boldsymbol{\varepsilon}}$ has two parts - elastic part $\dot{\boldsymbol{\varepsilon}}_{\mathrm{e}}$ and inelastic part $\dot{\boldsymbol{\varepsilon}}_{\mathrm{p}}$ :

$$
\dot{\boldsymbol{\varepsilon}}=\dot{\boldsymbol{\varepsilon}}_{e}+\dot{\boldsymbol{\varepsilon}}_{p}
$$

It is assumed that elastic strain $\dot{\boldsymbol{\varepsilon}}_{\mathrm{e}}$ obeys Hook's law and can be obtained by the relation:

$$
\dot{\boldsymbol{\varepsilon}}_{e}=\frac{1+v}{E} \dot{\boldsymbol{\sigma}}-\frac{v}{E}(\operatorname{tr} \dot{\boldsymbol{\sigma}}) \boldsymbol{I}
$$

where $E$ and $v$ are the Young's modulus and the Poisson's ratio of the material, $\boldsymbol{\sigma}$ and $\boldsymbol{I}$ stress tensor and the unit tensor of rank two respectively, and $t r$ the trace.

The inelastic strain $\boldsymbol{\varepsilon}_{p}$ represents both plastic and creep strains. A power relationship is adopted for the viscopotential and the viscoplastic strain rate $\dot{\boldsymbol{\varepsilon}}_{p}$ is expressed as in (Jiang et al. 2014):

$$
\dot{\boldsymbol{\varepsilon}}_{p}=\left\langle\frac{f}{Z}\right\rangle^{n} \frac{\partial f}{\partial \boldsymbol{\sigma}}
$$

where $f$ is the yield function, $Z$ and $n$ are material constants, and the bracket is defined by:

$$
\langle x\rangle=\left\{\begin{array}{l}
x, x \geq 0 \\
0, x<0
\end{array}\right.
$$

According to the von Mises yield criterion, the yield function $f$ is defined as

$$
f(\boldsymbol{\sigma}, \boldsymbol{\alpha}, R, k)=J(\boldsymbol{\sigma}-\boldsymbol{\alpha})-R-k \leq 0,
$$

where $\boldsymbol{\alpha}$ is the non-linear kinematic hardening variable, $R$ is the isotropic hardening variable and $k$ is the initial value of the radius of the yield surface. $J$ denotes the von Mises distance in the deviatoric stress space

$$
J(\boldsymbol{\sigma}-\boldsymbol{\alpha})=\sqrt{\frac{3}{2}\left(\boldsymbol{\sigma}^{\prime}-\boldsymbol{\alpha}^{\prime}\right):\left(\boldsymbol{\sigma}^{\prime}-\boldsymbol{\alpha}^{\prime}\right)}
$$

where $\boldsymbol{\sigma}^{\prime}$ and $\boldsymbol{\alpha}^{\prime}$ are the deviators of $\boldsymbol{\sigma}$ and $\boldsymbol{\alpha},:$ represents the inner product of two tensors. Plastic flow occurs under the condition $f=0$ and $\frac{\partial f}{\partial \boldsymbol{\sigma}}: \dot{\boldsymbol{\sigma}}>0$. For this model, the motion of yield surface continues to hold but the stress in excess of the yielding stress is now admissible and often termed as "overstress".

The evolution of the kinematic stress tensor $\boldsymbol{\alpha}$ and the isotropic stress $R$ may be described through the following rules (Chaboche 1989):

$$
\left\{\begin{array}{l}
\dot{\boldsymbol{\alpha}}=\dot{\boldsymbol{\alpha}}_{1}+\dot{\boldsymbol{\alpha}}_{2} \\
\dot{\boldsymbol{\alpha}}_{1}=C_{1}\left(a_{1} \dot{\boldsymbol{\varepsilon}}_{p}-\boldsymbol{\alpha}_{1} \dot{p}\right) \\
\dot{\boldsymbol{\alpha}}_{2}=C_{2}\left(a_{2} \dot{\boldsymbol{\varepsilon}}_{p}-\boldsymbol{\alpha}_{2} \dot{p}\right)
\end{array} \text { And } \dot{R}=b(Q-R) \dot{p}\right.
$$

where $C_{1}, a_{1}, C_{2}, a_{2}, b$ and $Q$ are six material and temperature dependent constants which determine the shape and amplitude of the stress-strain loops during the transient and saturated stage of cyclic response, and $\dot{p}$ is the accumulated inelastic strain rate defined by 
Table 1 Optimised parameter values for the viscoplastic constitutive model

\begin{tabular}{ll}
\hline Parameters & Optimised values \\
\hline$E(\mathrm{GPa})$ & 178.773 \\
$b$ & 6.37 \\
$Q(\mathrm{MPa})$ & 171.49 \\
$a_{1}(\mathrm{MPa})$ & 272.45 \\
$C_{1}$ & 2123.61 \\
$a_{2}(\mathrm{MPa})$ & 306.78 \\
$C_{2}$ & 2587.69 \\
$Z$ & 2018.32 \\
$n$ & 5.17 \\
$k(\mathrm{MPa})$ & 126.23 \\
\hline
\end{tabular}

$$
\dot{p}=\left\langle\frac{f}{Z}\right\rangle^{n}=\sqrt{\frac{2}{3} d \dot{\boldsymbol{\varepsilon}}_{p}: d \dot{\boldsymbol{\varepsilon}}_{p}}
$$

The constitutive equations contain eleven material parameters, namely, $E, v, k, b, Q, C_{1}, a_{1}, C_{2}, a_{2}, Z$ and $n$. The kinematic hardening behaviour is described by $C_{1}$, $a_{1}, C_{2}$ and $a_{2}$, where $a_{1}$ and $a_{2}$ are the saturated values of the kinematic hardening variables, and $C_{1}$ and $C_{2}$ indicate the speed with which the saturation is reached. The isotropic hardening is depicted by $Q$ and $b$, where $Q$ is the asymptotic value of the isotropic variable $R$ at saturation and $b$ indicates the speed towards the saturation. The initial size of the yield surface is represented by $k, E$ is the Young's modulus, $v$ is the Poisson's ratio, and $Z$ and $n$ are viscous parameters. The identification of material parameters began with a step-by-step procedure to obtain an initial set of parameters. These initial parameters are then used to obtain the optimised parameters in a simultaneous procedure. The experimental results, including monotonic, stress-relaxation and cyclic tests were used as inputs in a simultaneous identification procedure. The essence of this method is seeking a global minimum in the differences between the experimental data and corresponding simulation results. The parameter values, optimized from the uniaxial test data of LSHR at $725^{\circ} \mathrm{C}$, are listed in Table 1 . Comparisons of the experimental data and the model simulations are given in Figure 2a for monotonic tensile and stress relaxation behaviour (strain rate $=0.0083 \% / \mathrm{s}$, maximum strain $1 \%$ ) and in Figure $2 \mathrm{~b}$ for stabilized loop of a strain-controlled cyclic test (strain rate $=1 \% / \mathrm{s}$, strain range $\Delta \varepsilon=1 \%$ and strain ratio $=0)$. It can be seen that the simulations compare very well with the experimental results. The above material model has been programmed into a user defined material subroutine (UMAT) using a fully implicit integration and the Euler backward iteration algorithm, and implemented in the finite element software ABAQUS (Zhao \& Tong, 2008).

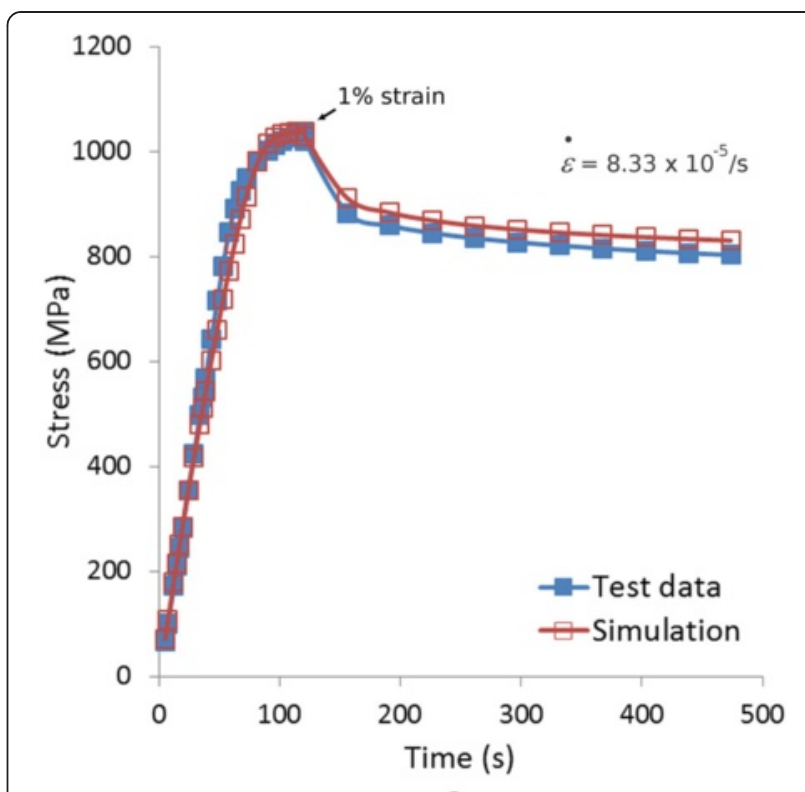

a

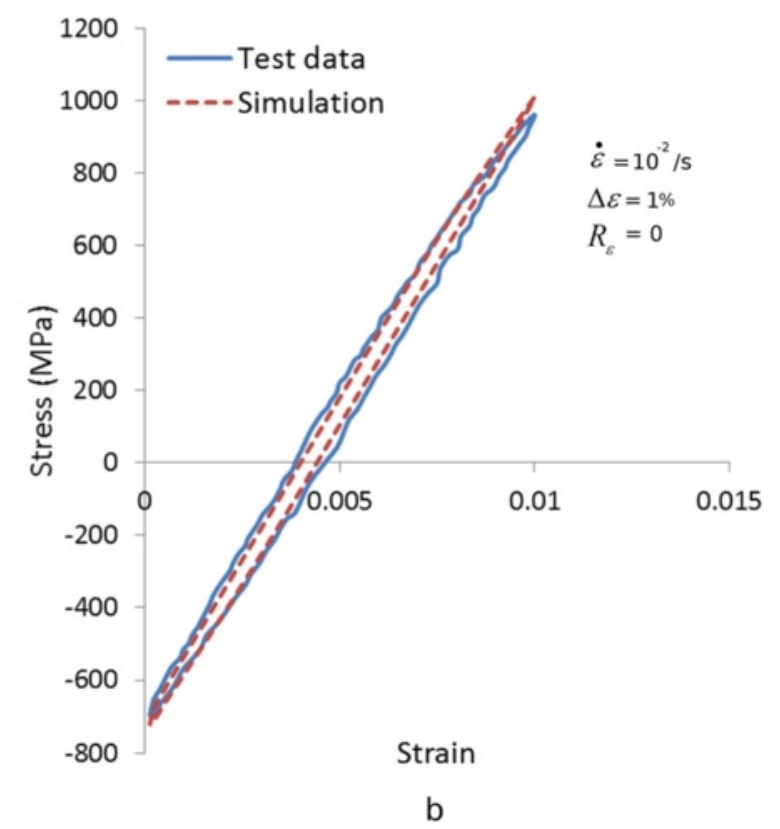

Figure 2 Comparison of model simulation and experimental data for (a) tensile behaviour up to $1 \%$ strain (strain rate dz/ $\mathrm{dt}=8.3 \times 10^{-5} / \mathrm{s}$ ), followed by stress relaxation for $500 \mathrm{~s}$ and (b) stabilized stress-strain loop under strain-controlled cyclic loading (strain rate $\mathrm{d} \varepsilon / \mathrm{dt}=10^{-2} / \mathrm{s}$, strain range $\Delta \varepsilon=1 \%$ and strain ratio $R_{\varepsilon}=0$ ).

\section{Finite element modelling}

\section{Stationary crack analysis}

A three-point bending specimen with dimensions shown in Figure 1a was considered for crack tip deformation analysis. The finite element mesh, as shown in Figure 3, consists of a combination of three-node and four-node 


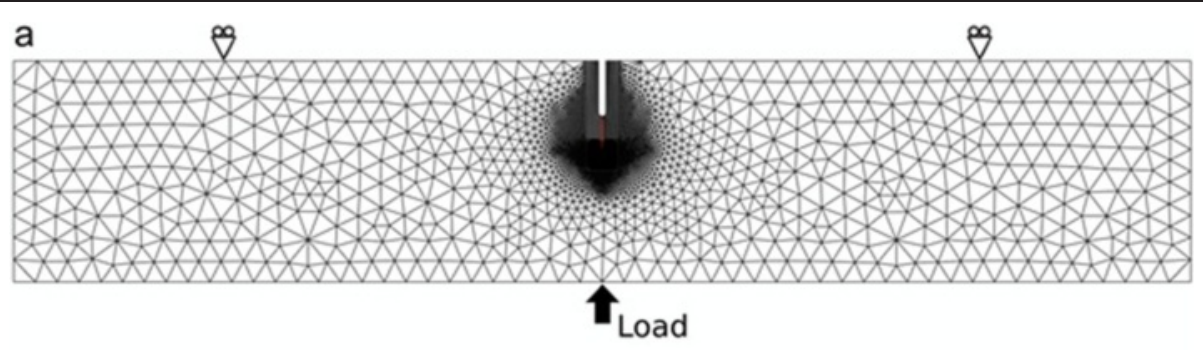

b

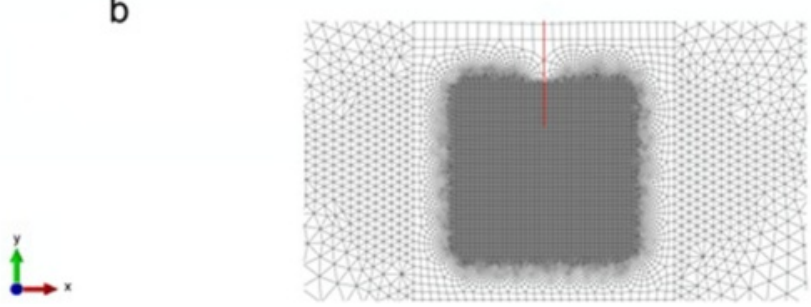

Figure 3 Finite element model for stationary crack analysis. (a) mesh for the SENB sample and (b) refined mesh near the crack tip (red line shows the crack).

first-order plane-strain elements with full integration. Two dimensional elements were chosen due to the prevailing plane-strain deformation of the specimen. Fournode fine elements, with size of $1 \mu \mathrm{m}$, were used near the crack-tip based on a convergency study. Cyclic load with a triangular waveform and a frequency of $0.5 \mathrm{~Hz}$ was applied to the middle node on the bottom side of the specimen (Figure 3), which is also constrained in the $\mathrm{x}$ direction to avoid the rigid body motion. While the two supports on the top side of the specimen are constrained in the y-direction to avoid rigid body rotation. For stationary crack analysis, the total crack length was chosen to be $a=4 \mathrm{~mm}$, i.e., $a / W=0.4$, which includes the notch with a depth of $2.5 \mathrm{~mm}$ and a precrack with a length of $1.5 \mathrm{~mm}$.
To verify the finite element model, stress intensity factors (SIF) were first computed, and the values are in total agreement with analytical solutions.

\section{XFEM analysis}

Analysis of the actual crack growth is hard to achieve using approaches such as cohesive zone element (CZE) and virtual crack closer technique (VCCT) due to the well-known fact that in these schemes the crack path has to be defined in advance. However, with the extended finite-element method (XFEM), a crack-propagation process can be modelled based on a solution-dependent criterion without introduction of a predefined path. In the XFEM, a crack is represented by enriching the classical displacement-based

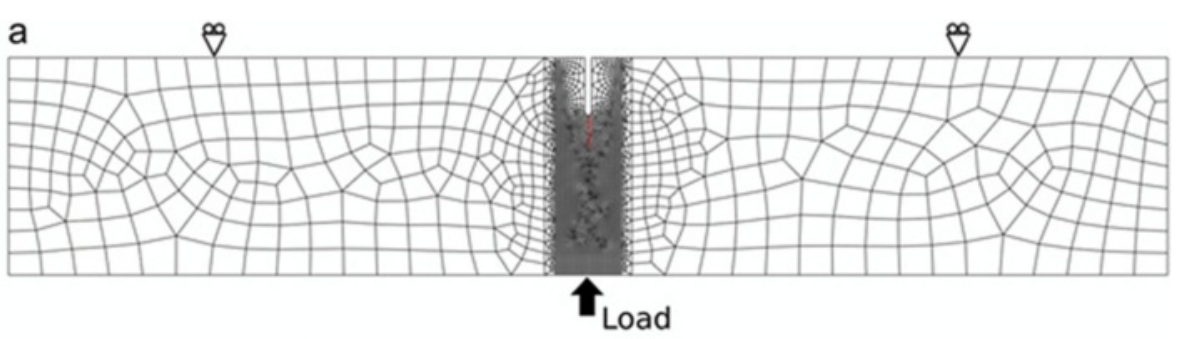

b
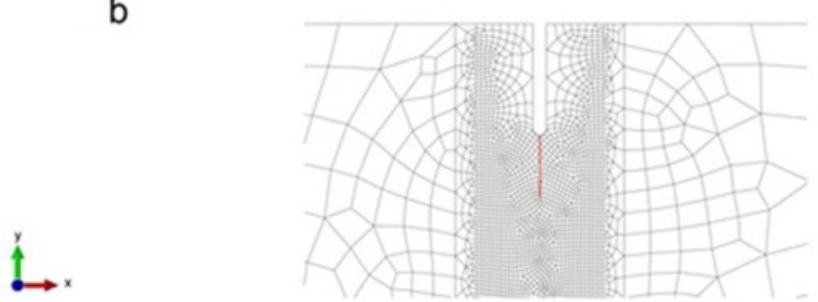

Figure 4 Finite element model for crack growth analysis. (a) mesh used for XFEM analysis and (b) refined mesh in crack growth area (red line shows the pre-crack). 
finite element approximation through the framework of partition of unity (Melenk \& Babuska 1996). A crack is modelled by enriching the nodes whose nodal shape function support intersects the interior of the crack by a discontinuous function, and enriching the nodes whose nodal shape function supports intersect the crack-tip by the twodimensional linear elastic asymptotic near-tip fields.

Again, the three-point bending specimen was considered and the finite element mesh for the specimen consists of purely four-node first-order plane-strain elements with full integration as shown in Figure 4. The initial notch $(2.5 \mathrm{~mm})$ and the precrack $(1.5 \mathrm{~mm})$ were introduced in the model, and XFEM enrichment was applied to the whole model that allows the crack to propagate through a solution dependent path determined by local material response. In Abaqus, the characteristic length refers to the size of element near the crack tip. This was evaluated based on mesh sensitivity study, for which three different element sizes along with two meshing schemes (free or structured) were considered. A consistent crack path was obtained for both meshing schemes with an average element size of $1 \mu \mathrm{m}$ in the crack growth zone. In this paper, free mesh (Figure 4) was used as it generated less number of elements to save computational time. The applied cyclic loading ratio $R$ was chosen to be 0.1 with value of $\Delta \mathrm{K}$ corresponding to the loading condition used for crack growth testing given in Section Experimental studies. In the present work, three different dwell times were considered, i.e. $1 \mathrm{~s}, 20 \mathrm{~s}$ and 90 s. A strain accumulation criterion was adopted in the model. It was assumed that the crack starts to grow when the accumulated plastic strain reaches a critical value at the crack tip. The crack growth direction is orthogonal to that of the maximum principal strain. During the simulation, an energy-based criterion was used to define the evolution of damage till eventual failure. In XFEM, the damage energy refers to critical energy release rate $G_{\text {critcal }}$ in fracture mechanics, which was calculated from the fracture toughness of LSHR at $725^{\circ} \mathrm{C}$ (in the range of $100 \mathrm{MPa} \sqrt{\mathrm{m}}$ ) using the following equation (ABAQUS 2012; Anderson 2005):

$$
G_{c r i t i c a l}=\frac{K_{I c}^{2}}{E}
$$

where $K_{I c}$ is the fracture toughness (critical stress intensity factor) and $E$ is the Young's modulus of the material. The value for the damage energy was calculated to be $56 \mathrm{~N} / \mathrm{mm}$. It should be noted that the fracture toughness (in the range of $100 \mathrm{MPa} \sqrt{\mathrm{m}}$ ) was estimated based on the values reported in literature on similar nickel alloys at high temperature (e.g. $650^{\circ} \mathrm{C}$ ) (Lin et al. 2011). The range was also confirmed with our industrial partner who supplied the material for this study. A linear law of damage evolution was adopted in this work after the

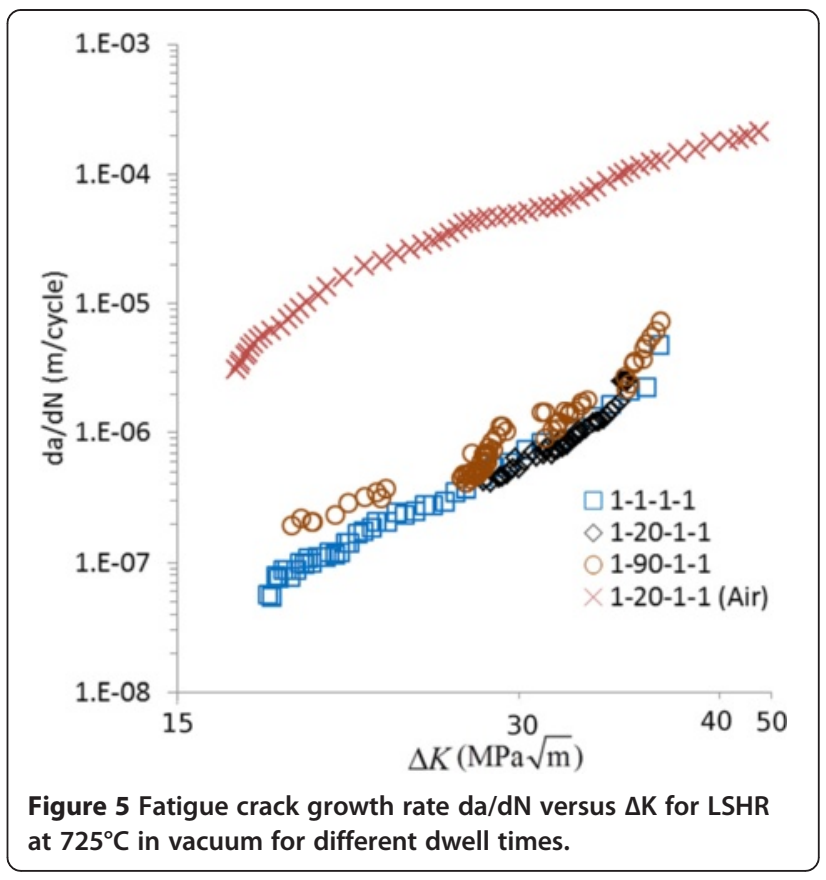

initiation of damage which refers to the beginning of degradation of the response of a material point when the energy criterion is satisfied. Basically, a scalar damage variable is used to represent the overall damage in the material, which initially has a value of 0 and monotonically evolves from 0 to 1 upon further loading after the initiation of damage. Consequently, the mechanical response of the material diminishes linearly until fracture.

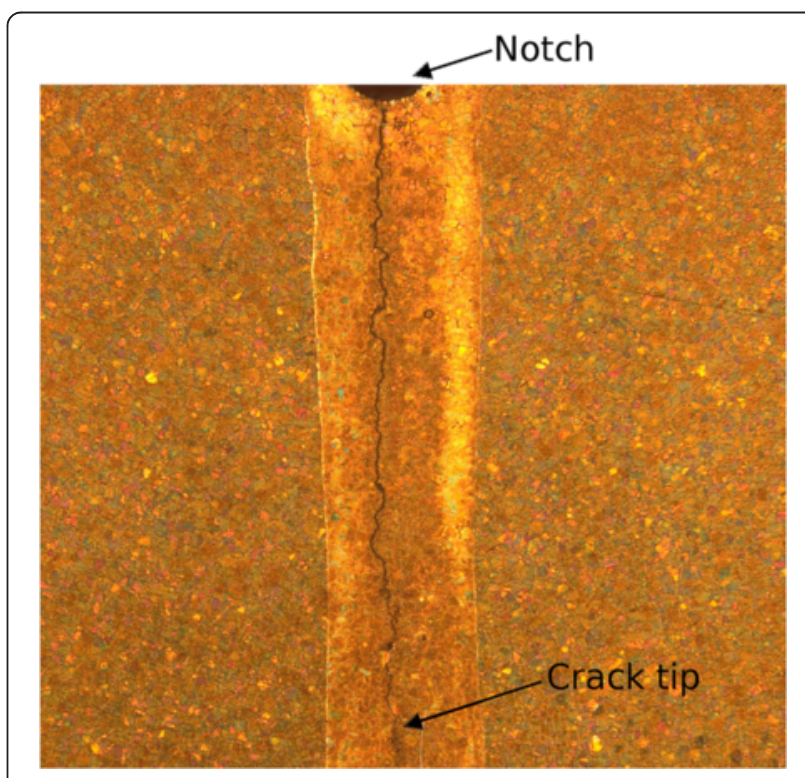

Figure 6 Image of crack propagation path under fatigue at $725^{\circ} \mathrm{C}$ in vacuum (1-20-1-1 waveform). 


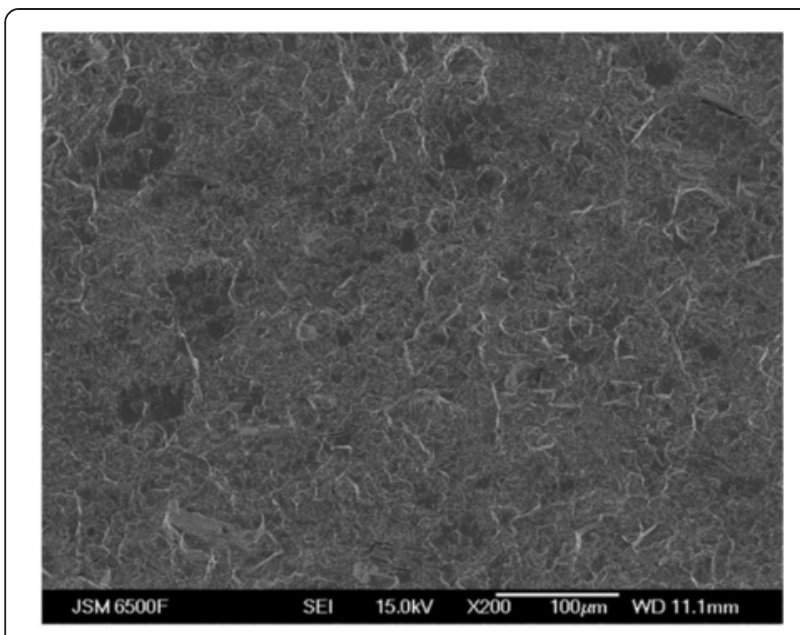

a

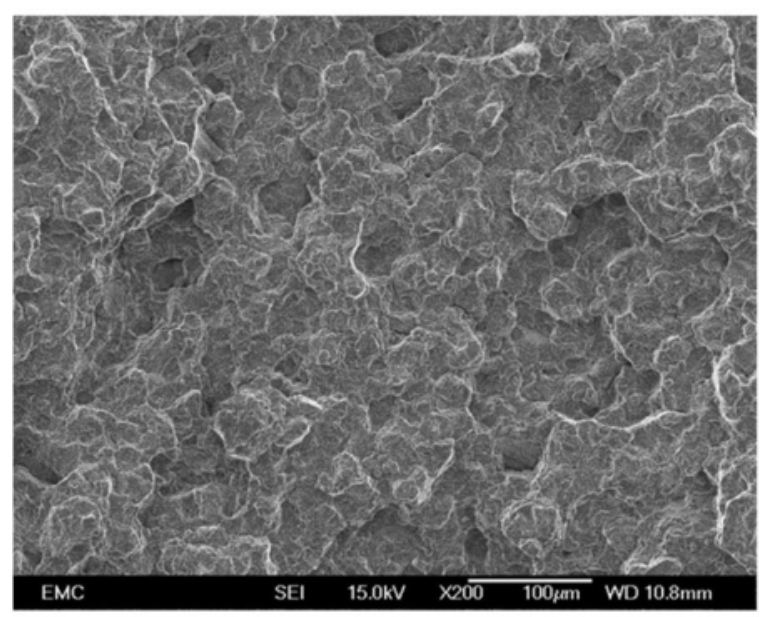

b

Figure 7 SEM images showing fracture surface of specimens tested under (a) 1-1-1-1 and (b) 1-90-1-1 waveforms at $725^{\circ} \mathrm{C}$ in vacuum.

\section{Results and discussion}

\section{Fatigue crack growth behaviour}

The long crack growth behaviour of LSHR as a function of dwell time has been considered. Figure 5 shows the fatigue crack growth (FCG) rates of LSHR superalloy tested at $725^{\circ} \mathrm{C}$ in vacuum for three different dwell times (1s, 20s and 90s). It was found that dwell time enhances fatigue crack propagation in vacuum conditions, but only slightly. Significantly higher da/dN values, by two to three orders, were observed for tests carried out in air than those in vacuum, especially for long dwell periods (Jiang et al. 2014). This is largely due to the detrimental effect of oxidation damage which attacks the grain boundaries, especially at the crack tip region, and induces accelerated crack propagation along the grain boundaries.

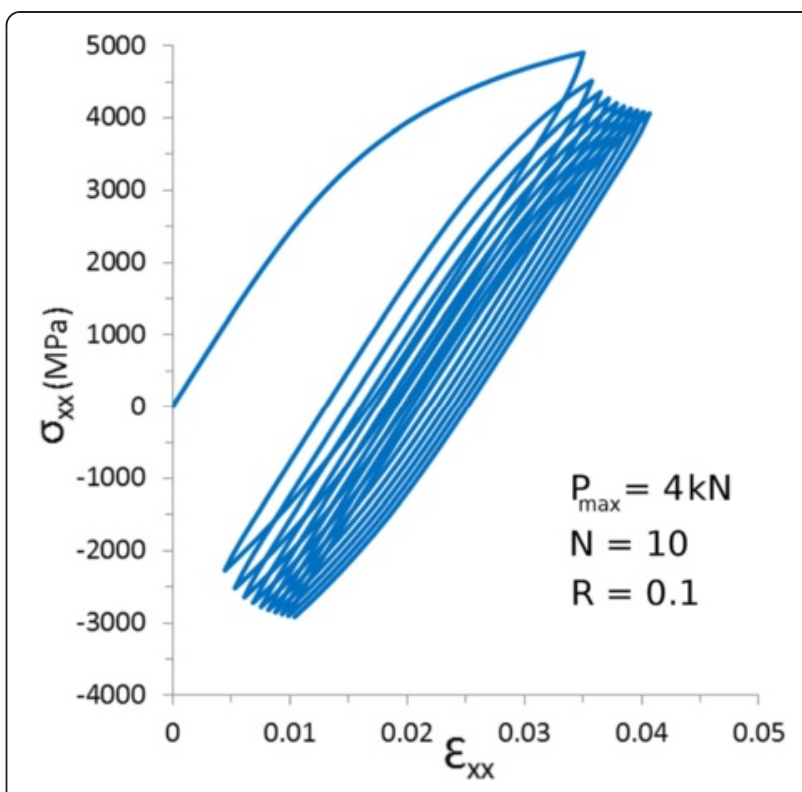

Figure 8 Evolution of normal stress-strain loops, averaged over the element just ahead of the crack tip, over 10 loading cycles (load ratio $R=0.1$, maximum load $\mathrm{P}_{\max }=4 \mathrm{kN}$ and number of cycles $\mathrm{N}=10$ ).

Systematic examination of the fracture surfaces was also carried out for tested specimens. The overall propagation of crack was along the centre line in all the cases as shown in Figure 6. Scanning electron microscopic analyses showed that fatigue crack growth is predominantly transgranular in vacuum (at temperature of interest) (see Figures $7 \mathrm{a}$ and b). However, intergranular cracking modes were also observed at longer dwell times (Figure 7b) indicating that creep assisted fatigue does occur in vacuum, but this is swamped by oxidation effects in air which accelerate the crack growth rates considerably via intergranular cracking mechanism (Jiang et al. 2014). In vacuum, the increase of dwell time may signify creep deformation, but does not change the mechanism which is controlled by the void formation and growth at grain boundaries, the cause of intergranular cracking.

\section{Fatigue crack-Tip deformation}

Crack tip deformation was studied by applying cyclic load to the 3-point bend stationary crack model (Figure 3). A total of ten cycles was simulated by considering a triangular loading waveform with a load ratio of $\mathrm{R}=0.1$, a maximum load of $4 \mathrm{kN}$ and a frequency of $0.5 \mathrm{~Hz}$. The load corresponds to a stress intensity factor range of $\Delta \mathrm{K}=31.6 \mathrm{MPa} \sqrt{\mathrm{m}}$.

Figure 8 shows the normal (in $\mathrm{x}$-direction) stressstrain loops averaged over the element just ahead of the crack tip. The stress and strain in the $\mathrm{x}$-direction are presented since they are perpendicular to the crack growth 


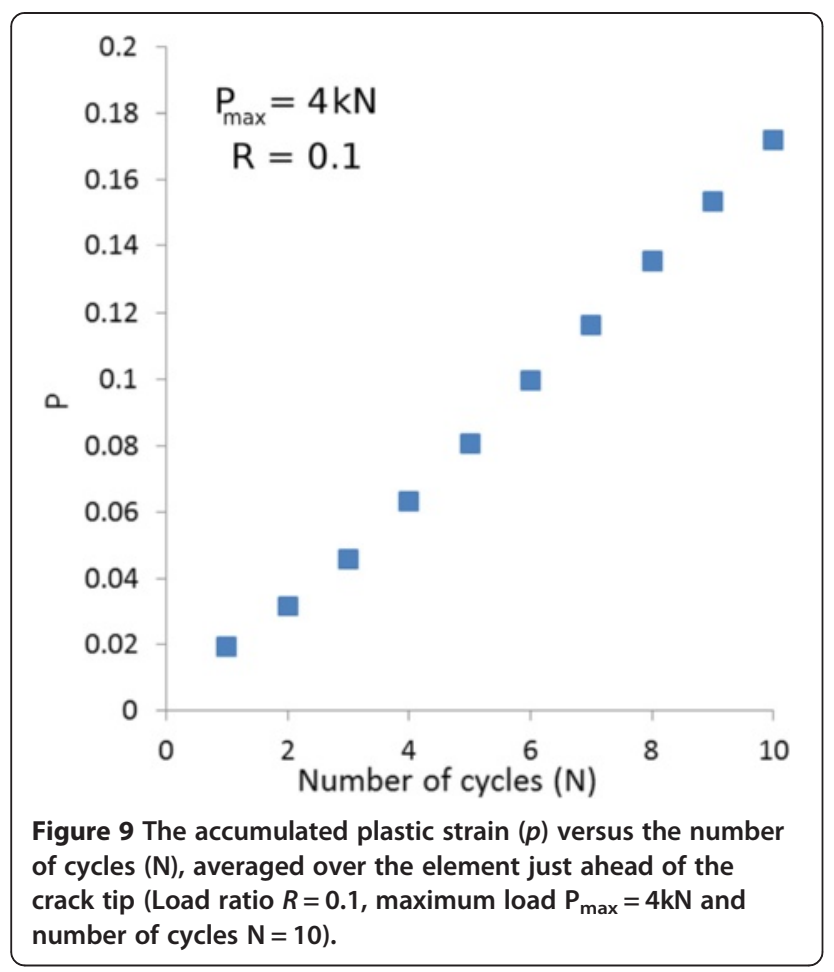

plane and most relevant to crack growth. It is noted that the stress-strain loops exhibit a progressive shift in the direction of increasing tensile strain, a phenomenon known as ratchetting or cyclic creep, where the plastic deformation during the loading portion is not balanced by an equal amount of yielding in the reverse loading direction. This phenomenon has been reported in our previous study of crack tip deformation. After 10 cycles, the normal strain reaches $\sim 4.1 \%$. The maximum stress is relaxed towards zero mean stress, while the shape and area of the stressstrain loops remained unchanged throughout the 10 cycles.

The continuous increase of tensile strain may be of particular significance for crack growth as it will eventually lead to material separation near the crack tip. Ratchetting has been increasingly recognised as a fatigue failure mechanism for metallic materials and alloys under cyclic stressing (Kapoor 1994; Yaguchi \& Takahashi 2005; Kang et al. 2006). In the near-tip stress-strain field, whilst the stress and the strain ranges remained essentially unchanged throughout the fatigue cycles, progressive accumulation of tensile strains occurred near the crack tip as shown in Figure 8. In fact, ratchetting behaviour is closely associated with plastic deformation which tends to accumulate during fatigue and introduce damage to the

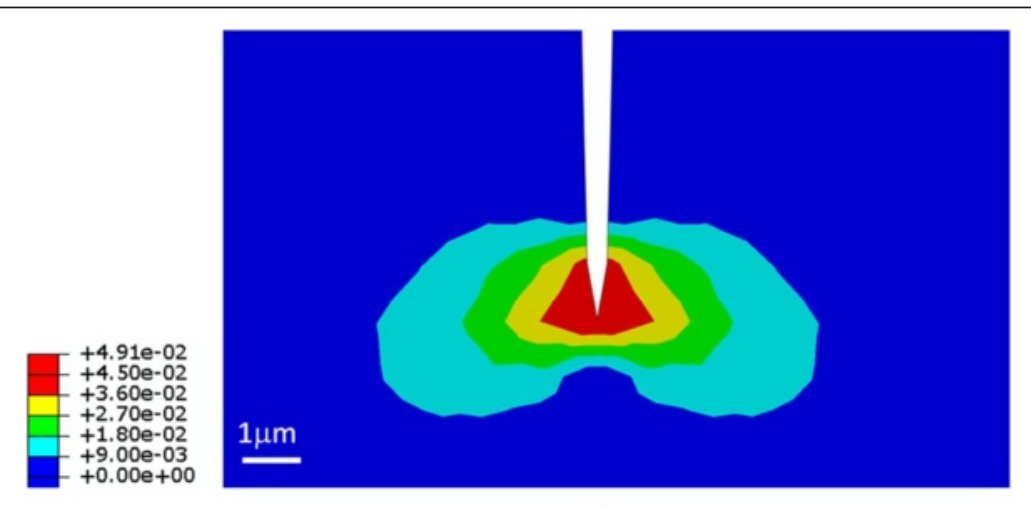

a

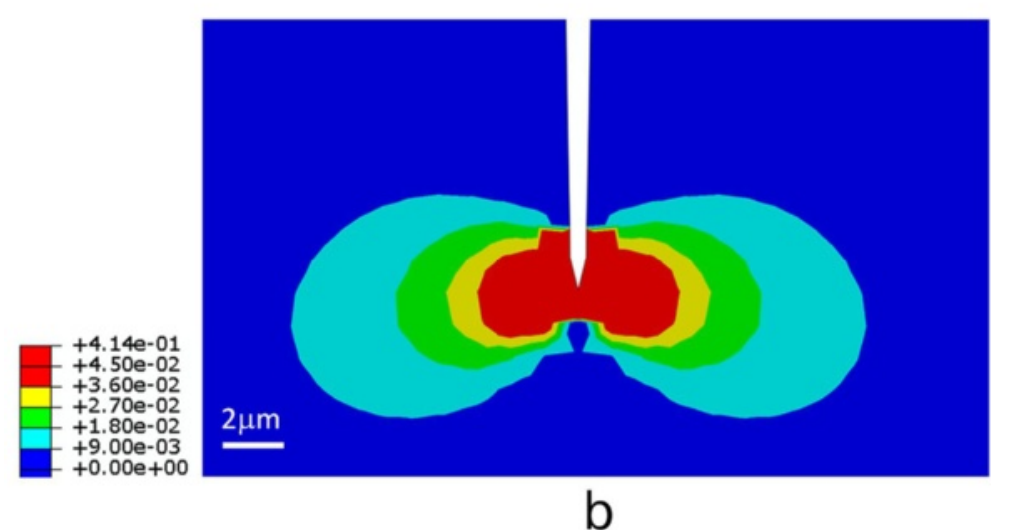

Figure 10 Contour plot of accumulate plastic strain near the crack tip at (a) the 1st cycle and (b) the 10th cycle for a triangular loading waveform $(\Delta \mathrm{K}=36.1 \mathrm{MPa} \sqrt{\mathrm{m}}, \mathrm{R}=0.1$ and $\mathrm{f}=0.25 \mathrm{~Hz})$. 
material near the crack tip, eventually leading to crack growth. The evolution of accumulated plastic strain with the number of cycle is shown in Figure 9, indicating its continuous increase during cyclic loading and hence suitability as a parameter to predict crack growth as presented in Section XFEM prediction of fatigue crack growth.

The crack growth criterion proposed above is essentially a strain-based approach, which has been widely used for the prediction of viscoplastic failures such as creep (Riedel \& Rice 1980; Yatomi et al. 2003; Zhao et al. 2006). For nickel alloys at $725^{\circ} \mathrm{C}$, the deformationcontrolled crack growth is a ductile fracture process, thus a strain-based parameter may be suitable to represent the contribution from mechanical deformation. The strains local to a crack tip are of multiaxial nature such that an equivalent strain, which accounts for all strain components, is often adopted as a damage parameter. In the current work, the accumulated plastic strain was considered, which also accounts for all plastic strain components (see Eq. 8). A contour plot of accumulated plastic strain near a fatigue crack tip is shown in Figures 10a and $\mathrm{b}$ for the first and the 10th loading cycles, respectively. It is noted that the accumulated inelastic deformation is highly localized in the vicinity of the crack tip. After 10 loading cycles, the maximum value has increased by almost 10 fold compared to that for the first cycle, i.e., increased from 0.049 to 0.414 . The choice of the accumulated plastic strain seems justified in that, under fatigue loadings, the reversed deformation during unloading is accounted for as well as that during loading.

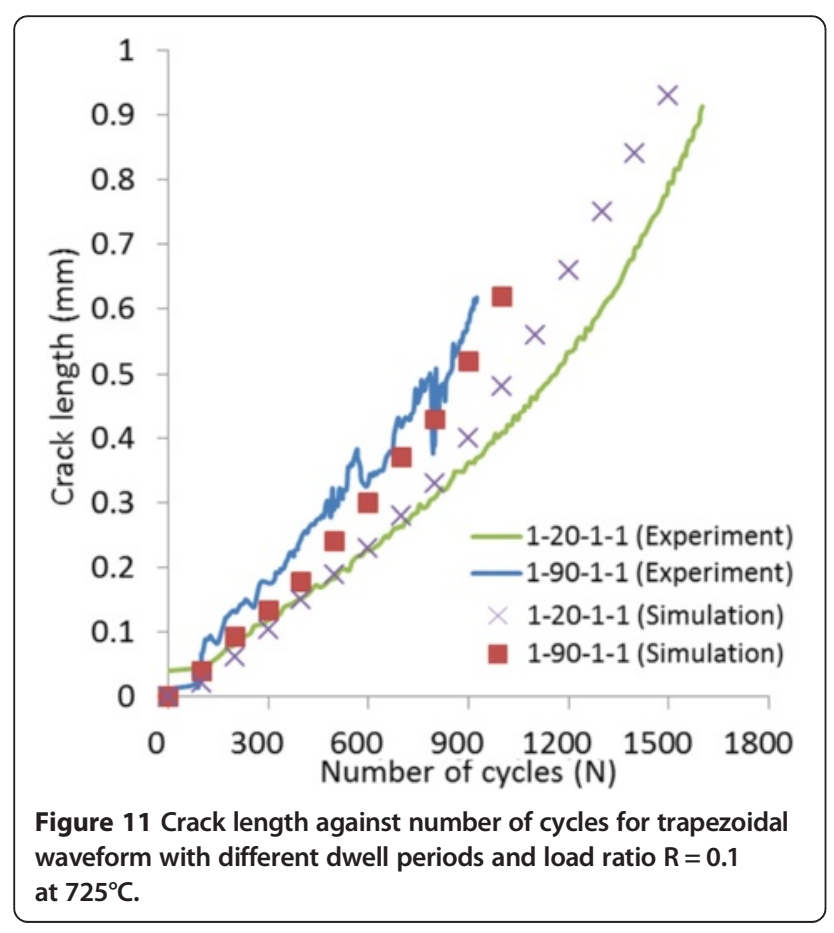

\section{XFEM prediction of fatigue crack growth}

To simulate a growing crack, three-point-bend loading conditions were applied to the specimen according to experiments. The load was kept constant and the value of $\Delta \mathrm{K}$ was constantly increasing with the increase of crack length. Simulations of crack growth were performed by considering three different dwell times (1s, 20s and 90s). During the simulation, the crack growth length was obtained by image processing. Accumulated plastic strain obtained by Eq. (8) was used as crack growth criterion. It was assumed that crack starts to grow when the plastic strain accumulation at the crack tip reached a critical value of 0.23 . This critical strain value was back calculated using finite element analysis, which predicts the same crack growth rate as the experimental results for a 1-20-11 fatigue test $\left(\mathrm{P}_{\max }=2.62 \mathrm{kN}\right.$ and $\left.R=0.1\right)$ at $725^{\circ} \mathrm{C}$ in vacuum.

Figure 11 shows the crack length vs number of cycles obtained from simulations, in comparison with the experimental results in vacuum. The use of vacuum results is necessary to remove the influence of oxidation, which can be considerable at elevated temperature, as the material model only considered the mechanical deformation. The variation in fatigue crack growth propagation caused by the changes in dwell time was similar to the experimental results. Obviously, the increase in crack growth rate with dwell time is linked to the creep deformation in the material. A good agreement between the simulation results and experimental data (Figure 11) shows the model's capability to predict crack growth in nickel-based alloy at high temperature. The crack propagation path predicted by the simulations is shown in Figure 12 . The crack propagates mainly along the centre line as also observed during the experiments (Figure 6), conforming to the highly constrained plane-strain condition of the specimen.

Figure 13 shows the predicted crack growth rates against $\Delta \mathrm{K}$ for the trapezoidal waveform with load ratio $\mathrm{R}=0.1$. Experimental data obtained from testing under the same loading conditions are also included for a comparison. From Figure 13, it can be seen that the predictions are reasonably close to the test data. The crack growth rate increase with the increase of dwell times due to the increased creep deformation for longer dwells. However, this effect is marginal when compared to the dwell effects under fatigue-oxidation conditions (Melenk \& Babuska 1996). The detrimental effects of environmental factors, in particular oxygen, on high-temperature crack growth behaviour in nickel alloys have been well demonstrated by experimental results (Ghonem \& Zheng 1992; Molins et al. 1997). For LSHR alloy, environmental effects were observed to modify the fracture morphology from transgranular to predominantly intergranular during fatigue crack growth, as well as to increase the growth 

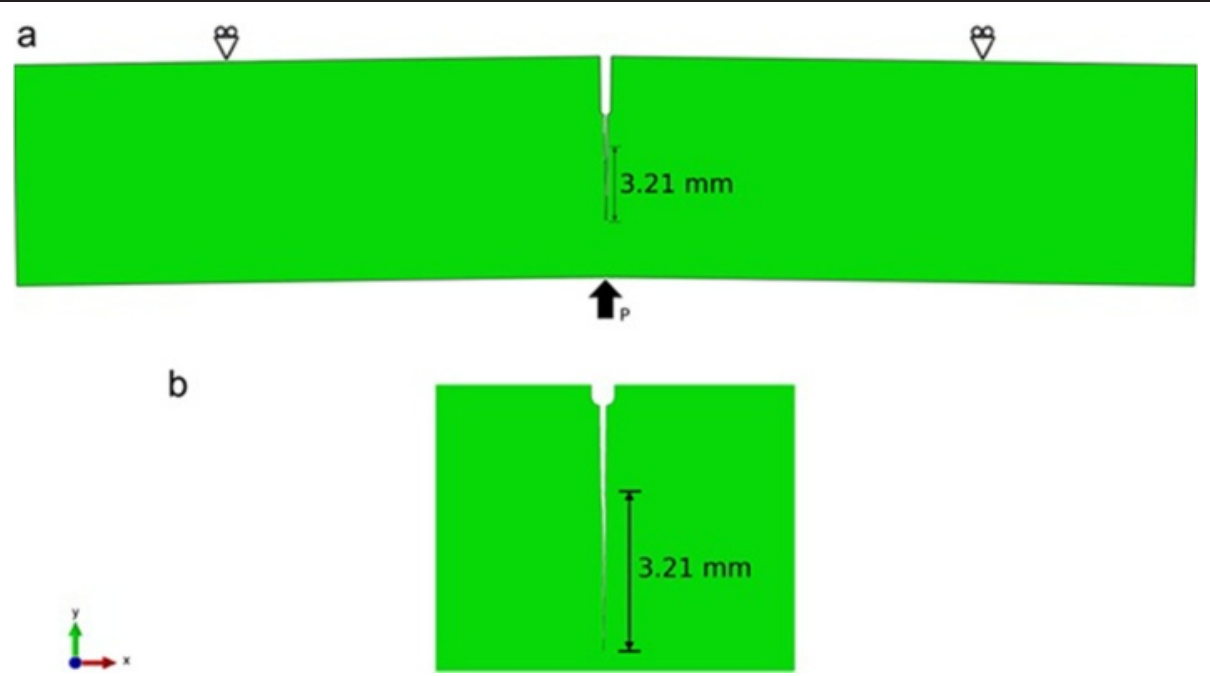

Figure 12 Simulated crack growth using XFEM. (a) crack propagation path (3.21 mm of growth length) and (b) zoomed-in crack growth path.

rates significantly at a given stress intensity (Melenk \& Babuska 1996). The effect of oxidation on crack growth is more pronounced at low frequencies and long dwell periods. Oxidation-accelerated crack growth is a direct consequence of oxygen diffusion into the material, which attacks the grain boundary through chemical reaction with alloy elements or oxygen segregation at grain boundaries. The diffusion process becomes more significant with the assistance of high tensile stress near crack tip, especially for superimposed dwell periods at the maximum load

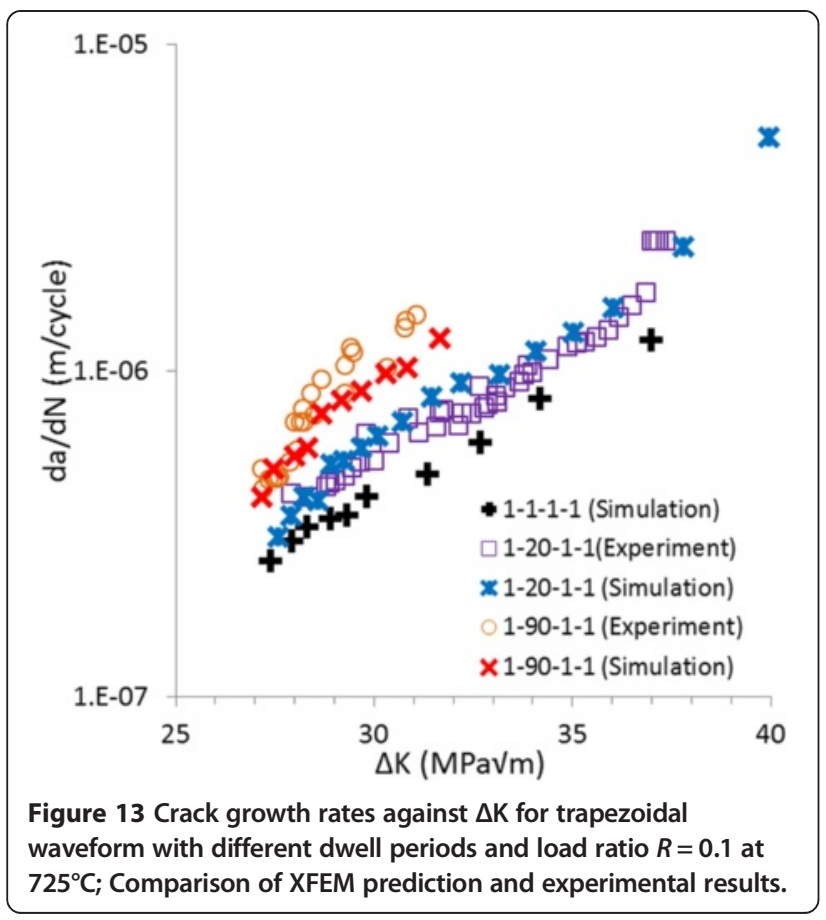

where the crack tip is fully open and experiences the highest tensile stress level. As a consequence, a coupled mechanical-diffusion analysis at microstructure level may be desirable to account for the effects of oxygen diffusion as well as that of viscoplasticity on crack growth (Carranza \& Haber 1999; Zhao et al. 2010).

Whilst the applied stress and instantaneous crack length are usually considered in the form of stress intensity factor range, the role of a characteristic fracture strain has not been well explored (Zhao \& Tong 2008). The strains local to a crack tip are of multiaxial nature such that an equivalent strain, which accounts for all strain components, is often adopted as a damage parameter which is also the case for the current work. The strain-based crack growth criterion is according to plastic strain accumulation at the crack tip, hence is more relevant to crack tip mechanics and the physical process of material damage. This criterion in combination with XFEM predicts reasonably well the crack growth rate. The present work is the first time that the accumulated plastic strain in combination with XFEM is used to predict the crack growth in superalloys at high temperature under fatigue loading. However, the XFEM prediction is limited to continuum level which is incapable of dealing with material micro-structural features and the influence of these features on the mechanical behaviour of the material. Alloy LSHR is a face-centred-cubic (f.c.c.) polycrystalline metallic alloy with a wide range of grain size and random grain orientation, which may also increase, decrease or arrest the crack growth (Pang \& Reed 2003; Suresh 1998). Further work is under way to predict crack growth in the presence of explicit grain microstructure by using a crystal plasticity model combined with XFEM technique. 
The current work considered three fatigue loading conditions with a frequency range of $0.01 \mathrm{~Hz}$ to $0.25 \mathrm{~Hz}$, for which the model works well. However, with the decrease of loading frequency, time-dependent creep deformation tends to become dominant and leads to the prevalence of intergranular cracking. In this case, the model prediction may not work well. Due to the lack of test data at very low frequencies, it is very difficult to tell at which frequency the model prediction may break down, and further work is required in future study.

\section{Conclusion}

Experimental study showed that dwell time enhances fatigue crack propagation in nickel alloy LSHR, but only slightly for vacuum conditions. Dwell effects are more considerable for tests carried out in air. This is largely due to the detrimental effect of oxidation damage which attacks the grain boundaries, especially at the crack tip region, and induces accelerated crack propagation along the grain boundaries, i.e., intergranular crack growth. Computational analyses of stationary crack showed the progressive accumulation of plastic strain near the crack tip, which has been subsequently used as a fracture criterion to predict crack growth using the extended finite element method (XFEM). This crack growth criterion was successful in predicting both the path and the rate of crack growth at selected loading range and dwell period. This work proved the capability of XFEM, in conjunction with advanced cyclic viscoplasticity constitutive model, for predicting crack growth in nickel alloys at elevated temperature, which has significant implication to gas turbine industries in terms of "damage tolerance" assessment of critical turbine discs and blades made of nickel alloys.

\section{Competing interests}

The authors declare that they have no competing interests.

\section{Authors' contribution}

FF planned and carried out this study and drafted the manuscript. RJ and DP carried out the experimental part of this study. PR, BS and LZ supervised the research, contributed to the interpretation of results and writing of the manuscript. All the authors read and approved the manuscript.

\section{Acknowledgements}

The work was funded by the EPSRC (Grants EP/K026844/1, EP/K027271/1 and EP/K027344/1) of the UK and in collaboration with Nasa, Alstom, E.On and Dstl. Research data for this paper is available on request from the project principal investigator Dr Liguo Zhao at Loughborough University (email: L.Zhao@Lboro.ac.uk).

\section{Author details}

${ }^{1}$ Wolfson School of Mechanical and Manufacturing Engineering, Loughborough University, Loughborough LE11 3TU, UK. ${ }^{2}$ Materials Group, Engineering and the Environment, University of Southampton, Southampton SO17 1BJ, UK. ${ }^{3}$ Department of Materials, Imperial College, London SW7 2AZ, UK. ${ }^{4}$ Warwick Manufacturing Group, University of Warwick, Coventry CV4 7AL, UK.
Received: 25 November 2014 Accepted: 22 January 2015

Published online: 05 May 2015

\section{References}

Pang HT, Reed PAS (2003) Fatigue crack initiation and short crack growth in nickel-base turbine disc alloys - the effects of microstructure and operating parameters. Int J Fatigue 25:1089-1099

Dalby S, Tong J (2005) Crack growth in a new nickel-based superalloy at elevated temperature, part I: effects of loading waveform and frequency on crack growth. J Mater Sci 40:1217-1228

Suresh S (1998) Fatigue of Materials. Cambridge University Press, Cambridge, UK

Sehitoglu H, Sun W (1989) The significance of crack closure under high temperature fatique crack growth with hold periods. Eng Fract Mech 33:371-388

Pommier S, Bompard P (2000) Bauschinger effect of alloys and plasticity-induced crack closure: A finite element analysis. Fatigue Fract Eng Mater Struct 23:129-139

Zhao LG, Tong J, Byrne J (2004) The evolution of the stress-strain fields near a fatigue crack tip and plasticity-induced crack closure revisited. Fatigue Fract Eng Mater Struct 27:19-29

Zhao LG, Tong J (2008) A viscoplastic study of crack-tip deformation and crack growth in a nickel-based superalloy at elevated temperature. J Mech Phys Solids 56:3363-3378

Moës N, Dolbow J, Belytschko T (1999) A finite element method for crack growth without remeshing. Int J Numer Meth Eng 46:131-150

Dolbow J, Moës N, Belytschko T (2001) An extended finite element method for modeling crack growth with frictional contact. Comp Meth Appl Mech Eng 190:6825-6846

Daux C, Moës N, Dolbow J, Sukumar N, Belytschko T (2001) Arbitrary branched and intersecting cracks with the extended finite element method. Int J Numer Meth Eng 48:1741-1760

Dolbow J, Moës N, Belytschko T (2000) Modeling fracture in Mindlin- Reissner plates with the extended finite element method. int J Solids Structures 37:7161-7183

Belytschko T, Chen H, Xu J, Zi G (2003) Dynamic crack propagation based on loss of hyperbolicity and a new discontinuous enrichment. Int J Numer Meth Eng 58:1873-1905

Sukumar N, Chopp DL, Moës N, Belytschko T (2001) Modeling holes and inclusions by level sets in the extended finite element method. In J Numer Meth Eng 50:993-1013

Moës N, Cloirec M, Cartraud P, Remacle J-F (2003) A computational approach to handle complex microstructure geometries. Comput Meth Appl Mech Eng 192:3163-3177

Chessa J, Smolinski P, Belytschko T (2002) The extended finite element method (XFEM) for solidification problems. Int J Numer Meth Eng 53:1959-1977

Samaniego E, Belytschko T (2005) Continuum-discontinuum modelling of shear bands. Int J Numer Meth Eng 62:1857-1872

Stolarska M, Chopp DL, Moës N, Belytschko T (2001) Modelling crack growth by level sets in the extended finite element method. Int J Numer Meth Eng 51:943-960

Mariani S, Perego U (2003) Extended finite element method for quasi-brittle fracture. Int J Numer Meth Eng 58:103-126

Bellec J, Dolbow J (2003) A note on enrichment functions for modeling crack nucleation. Commun Numer Meth Eng 19:921-932

Budyn E, Zi G, Moës N, Belytschko T (2004) A method for multiple crack growth in brittle materials without remeshing. Int I Numer Meth Eng 61:1741-1770

Ventura G, Budyn E, Belytschk T (2003) Vector level sets for description of propagating cracks in finite elements. Int J Numer Meth Eng 58:1571-1592

Nagashima T, Omoto T, Tani S (2003) Stress intensity factor analysis of interface cracks using XFEM. Int J Numer Meth Eng 56:1151-1173

T.P. Gabb, J. Gayda, J. Telesman (2005) Thermal and mechanical property characterization of the advanced disk alloy LSHR, NASA report NASATM2005-213645

Jiang R, Everitt S, Lewandowski M, Gao N, Reed PAS (2014) Grain size effects in a Ni-based turbine disc alloy in the time and cycle dependent crack growth regimes. Int J Fatigue 62:217-227

Chaboche JL (1989) Constitutive equations for cyclic plasticity and cyclic viscoplasticity. Int J Plasticity 5:247-302

Melenk JM, Babuska I (1996) The partition of unity finite element method: Basic theory and applications. Comput Meth Appl Mech Eng 139:289-314

ABAQUS, Version 6.12 User's manual, SIMULIA, Providence, Rl, 2012 
T. L. Anderson (2005) Fracture Mechanics: Fundamentals and Applications, Taylor \& Francis, USA

Lin B, Zhao LG, Tong J (2011) A crystal plasticity study of cyclic constitutive behaviour, crack-tip deformation and crack-growth path for a polycrystalline nickel-based superalloy. Eng Fract Mech 78:2174-2192

Kapoor A (1994) A re-evaluation of the life to rupture of ductile metals by cyclic plastic strain. Fatigue Fract Eng Mater Struct 17:201-219

Yaguchi M, Takahashi Y (2005) Ratchetting of viscoplastic material with cyclic softening, Part I: experiments on modified 9Cr-1Mo steel. Int J Plast 21:43-65

Kang G, Liu Y, Li Z (2006) Experimental study on ratcheting-fatigue interaction of SS304 stainless steel in uniaxial cyclic stressing. Mater Sci Eng A 435436:396-404

Riedel H, Rice JR (1980) Tensile cracks in creeping solids. ASTM STP 700:112-130

Yatomi M, Nikbin KM, O'Dowd NP (2003) Creep crack growth prediction using damage based approach. Int J Press Vessels Piping 80:573-583

Zhao LG, O'Dowd NP, Busso EP (2006) A coupled kinetic-constitutive approach to the study of high temperature crack initiation in single crystal nickel-base superalloys. J Mech Phys Solids 54:288-309

Ghonem H, Zheng D (1992) Depth of intergranular oxygen diffusion during environment-dependent fatigue crack growth in alloy 718. Mater Sci Eng A150:151-160

Molins R, Hochestetter G, Chassaigne JC, Andrieu E (1997) Oxidation effects on the fatigue crack growth of alloy 718 at high temperature. Acta Mater 45:663-674

Carranza FL, Haber RB (1999) A numerical study of intergranular fracture and oxygen embrittlement in an elastic-viscoplastic solid. J Mech Phys Solids 47:27-58

Zhao LG, Tong J, Hardy MC (2010) Prediction of crack growth in a nickel-based superalloy under fatigue-oxidation conditions. Eng Fract Mech 77:925-938

\section{Submit your manuscript to a SpringerOpen ${ }^{\circ}$ journal and benefit from:}

- Convenient online submission

- Rigorous peer review

- Immediate publication on acceptance

- Open access: articles freely available online

- High visibility within the field

- Retaining the copyright to your article

Submit your next manuscript at $>$ springeropen.com 